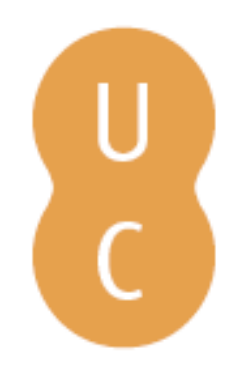

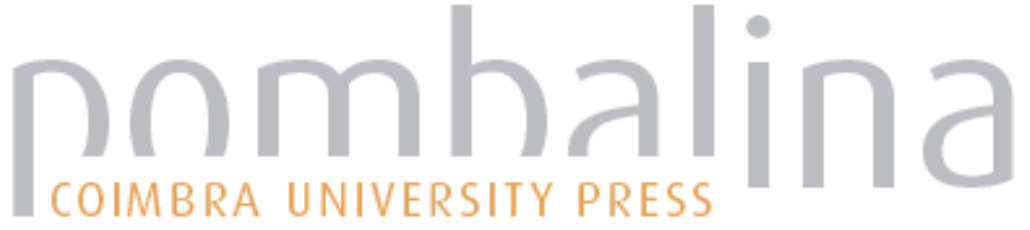

Estabilidade da scorodite perante efluentes mineiros: exemplos do Norte de Portugal

Autor(es): $\quad$ Alves, R. M. Cepeda; Gomes, C. A. Leal; Valente, T. M.

Publicado por: Imprensa da Universidade de Coimbra

URL

persistente: URI:http://hdl.handle.net/10316.2/31463

DOI: $\quad$ DOI:http://dx.doi.org/10.14195/978-989-26-0534-0_35

Accessed : $\quad$ 26-Apr-2023 10:47:25

A navegação consulta e descarregamento dos títulos inseridos nas Bibliotecas Digitais UC Digitalis, UC Pombalina e UC Impactum, pressupõem a aceitação plena e sem reservas dos Termos e Condições de Uso destas Bibliotecas Digitais, disponíveis em https://digitalis.uc.pt/pt-pt/termos.

Conforme exposto nos referidos Termos e Condições de Uso, o descarregamento de títulos de acesso restrito requer uma licença válida de autorização devendo o utilizador aceder ao(s) documento(s) a partir de um endereço de IP da instituição detentora da supramencionada licença.

Ao utilizador é apenas permitido o descarregamento para uso pessoal, pelo que o emprego do(s) título(s) descarregado(s) para outro fim, designadamente comercial, carece de autorização do respetivo autor ou editor da obra.

Na medida em que todas as obras da UC Digitalis se encontram protegidas pelo Código do Direito de Autor e Direitos Conexos e demais legislação aplicável, toda a cópia, parcial ou total, deste documento, nos casos em que é legalmente admitida, deverá conter ou fazer-se acompanhar por este aviso. 



\title{
ESTABILIDADE DA SCORODITE PERANTE EFLUENTES MINEIROS EXEMPLOS DO NORTE DE PORTUGAL
}

\author{
SCORODITE STABILITY IN MINE DRAINAGE \\ NORTHERN PORTUGAL EXAMPLES
}

R. M. Cepeda Alves', C. A. Leal Gomes² \& T. M. Valente ${ }^{3}$

\begin{abstract}
Resumo - Apresenta-se uma síntese de resultados procedentes de um programa alargado de reconhecimento de neoformaçóes mineralógicas em rejeitos mineiros. Neste caso deu-se especial atenção às paragéneses secundárias em que a scorodite $\left(\mathrm{FeAs}_{4} \cdot 2 \mathrm{H}_{2} \mathrm{O}\right)$ é fase essencial, ocorrendo sob a forma de cristais isolados, agregados ou ainda em crustificaçóes com diferentes estados de consolidação e níveis de compacidade. Foram selecionados espaços mineiros do $\mathrm{N}$ de Portugal, com depósitos hidrotermais de quartzo com sulfuretos metálicos: Castelhão, Argas-Cerquido, Tibães, Adoria e Penedono. Foram analisadas águas de efluente mineiro afetadas pela interação com escombreiras e escavações, e comparadas com águas do fundo regional de cada um dos espaços mineiros. Nos casos estudados, dependendo da interação água - mineral e na sequência da oxidação da arsenopirite, as águas de embebimento e escorrência seguem uma tendência definida até às condiçôes de sobre-saturação e precipitaçáo da scorodite, para um incremento de Eh e decréscimo de $\mathrm{pH}$, a Eh>150 mV e [As] > 90ppb.
\end{abstract}

Palavras-chave - Scorodite; Oxidação da arsenopirite; Sequestro metálico

Abstract - This work synthesizes some results of an extended program of recognition of minerals newly formed in mine wastes and diggings. In this case, it deals with the secondary paragenesis holding scorodite $\left(\mathrm{FeAs}_{4} \cdot 2 \mathrm{H}_{2} \mathrm{O}\right)$ as an essential species, occurring as isolated crystals, aggregates or crusts, with different degrees of consolidation and compaction. The selected mining sites, in North-

1 Centro de Investigação Geológica, Ordenamento e Valorização de Recursos (CIG-R) - Escola de Ciências - Departamento de Ciências da Terra - Universidade do Minho, Portugal; raquelmcepedaalves@gmail.com

2 Escola de Ciências - Departamento de Ciências da Terra - Universidade do Minho, Portugal; caal.gomes@gmail.com

3 CIG-R - Escola de Ciências - Departamento de Ciências da Terra - Universidade do Minho, Portugal; teresav@dct.uminho.pt 
ern Portugal, corresponded to sulphide+quartz hydrothermal veins and mineralizations: Castelhão, Argas-Cerquido, Tibães, Adoria and Penedono. Mining effluents affected by the waste dumps, and the background water in each site were analysed. In the studied effluents, depending on the conditions of water-mineral interaction and arsenopirite oxidation, the composition of affected solutions follow a definite path, till de oversaturation and scorodite precipitation: increasing Eh / decreasing $\mathrm{pH}$ at Eh>150mV and As concentration higher than 90 ppb.

Keywords - Scorodite; Arsenopyrite oxidation; Metal sequester

\section{1 - Introdução}

Os espaços mineiros selecionados para este estudo correspondem a jazigos hidrotermais filonianas ou venulares relacionadas com zonas de cisalhamento, em que as paragéneses primárias incluem quartzo e sulfuretos e em que a aresenopirite, sempre presente, pode ser um dos sulfuretos mais abundantes. As rochas encaixantes são de tipo metassedimentar a metavulcânico ou então são granitóides.

As tecnologias de extração e o tratamento dos "tout venants", que se diferenciaram no tempo, distinguem os vários sítios mineiros, em especial, pelas características da cominuição e consequente superfície específica, que estão expressas nos estéreis rejeitados e acumulados em escombreiras: Mina do Fuláo, situada na zona de cisalhamento de Argas-Cerquido; Mina de Castelhão; Mina de Tibães; Mina do Monte de Entre-Portelas - Couto Mineiro de Adoria; Mina de Sto. António - Penedono, localizadas na Fig. 1.

Com a exceção de Penedono, as restantes minas têm pequena dimensão. Lavra e tratamento de minérios rudimentares geraram estéreis grosseiros.

Em Penedono verificou-se um esquema de tratamento de minérios, tecnologicamente mais moderno e elaborado, o qual originou estéreis de calibre muito mais fino, quando comparado com aquele que está acumulado nas escombreiras dos restantes locais.

Em todos estes espaços mineiros a scorodite é ubíqua e é também o produto mais persistente da alteração supergénica da arsenopirite. A sua abundância é variável, estando conjugada com o conteúdo modal de arsenopirite que ocorre nos diversos minérios primários.

A descrição das paragéneses portadoras de scorodite e das suas ancestrais primárias encontra-se na tabela 1 . Na tabela 2 discriminam-se os modos de ocorrência da scorodite.

\section{2 - Metodologia}

A colheita de amostras incidiu sobre escombreiras e outros trabalhos com resíduos de calibre variável, maioritariamente grosseiros a muito grosseiros, com evidências claras da oxidação da arsenopirite e de outros sulfuretos.

Recolheram-se efluentes que interagiram com estes resíduos e ainda outras águas, de escorrência e embebimento afetadas, ou não, pelos trabalhos mineiros e, eventualmente, coexistentes com paragéneses portadoras de scorodite.

O programa de caracterização mineralógica de escombreiras seguiu a metodologia de trabalho estabelecida em VALENTE \& LEAL GOMES (1998) e foi desenvolvido em ALVES et al. (2010). 


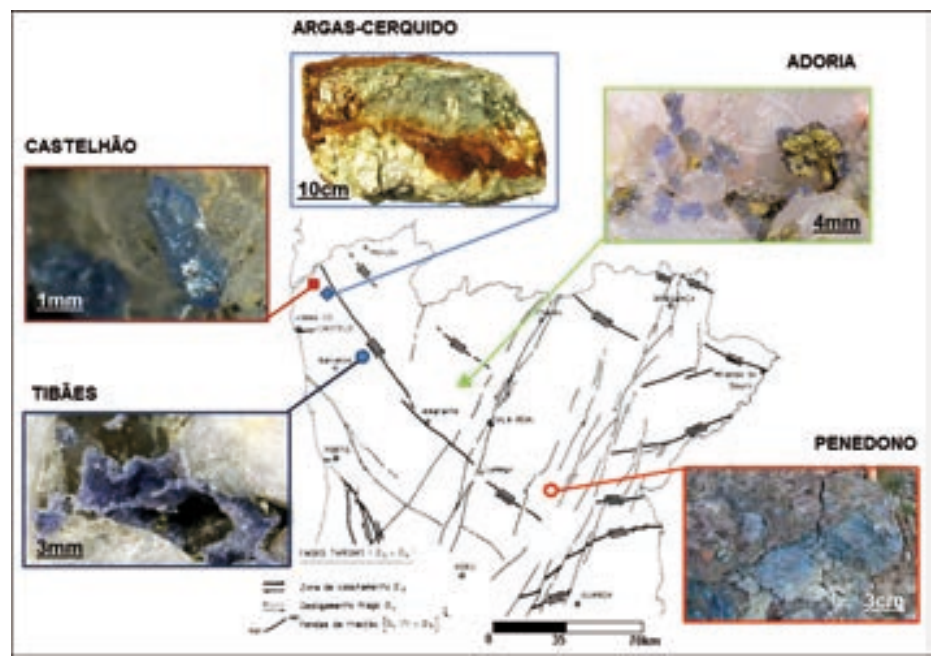

Fig. 1 - Localização dos espaços mineiros estudados - microfotografias selecionadas para alguns tipos característicos dos modos de ocorrência da scorodite (ilustram alguns dos aspetos considerados na tabela 2).

Tabela 1 - Paragéneses típicas dos diferentes ambientes mineiros onde ocorre scorodite.

\begin{tabular}{|c|c|c|}
\hline $\begin{array}{l}\text { Espaço } \\
\text { mineiro }\end{array}$ & Paragénese primária & Paragénese secundária \\
\hline Castelhão & $\begin{array}{l}\text { pirite/marcassite }>\text { arsenopirite }>> \\
\text { volframite }>\text { blenda }\end{array}$ & $\begin{array}{l}\text { scorodite }>\text { goethite }>> \\
\text { farmacossiderite }> \\
\text { enxofre nativo }\end{array}$ \\
\hline $\begin{array}{l}\text { Argas- } \\
\text {-Cerquido }\end{array}$ & $\begin{array}{c}\text { arsenopirite }>\text { pirite }> \\
\text { blenda }>\text { galena }>\text { calcopirite }> \\
\text { volframite }>>\text { scheelite }> \\
\text { tungstatos de } \mathrm{Pb}\end{array}$ & $\begin{array}{c}\text { goethite } \approx \text { scorodite }>> \\
\text { beudantite-segnitite }>\text { mimetite }>\text { carminite }> \\
\text { rooseveltite }>\text { arsenobismite }>\text { covellite }>\text { enxofre } \\
>\text { fosgenite }\end{array}$ \\
\hline Tibães & $\begin{array}{c}\text { arsenopirite }>\text { pirite }>\text { marcassite }> \\
\text { blenda }>\text { volframite }>\text { calcopirite }>> \\
\text { apatite }>\text { pirrotite }\end{array}$ & $\begin{array}{c}\text { goethite } \approx \text { scorodite }>\text { farmacossiderite }>\text { enxofre }> \\
\text { covellite }>\text { strengite }>>\text { yanomamite }\end{array}$ \\
\hline Adoria & $\begin{array}{c}\text { arsenopirite }>\text { pirite }> \\
\text { galena }>\text { blenda }>> \\
\text { volframite }>\text { cassiterite }>> \\
\text { calcopirite }\end{array}$ & $\begin{array}{l}\text { goethite } \approx \text { scorodite }>\text { beudantite }>\text { mimetite }> \\
\text { carminite }>\text { torbernite }>\text { anglesite }>\text { brochantite }\end{array}$ \\
\hline Penedono & $\begin{array}{c}\text { arsenopirite }>\text { pirite }> \\
\text { galena }>\text { blenda }\end{array}$ & fases metaestáveis $>$ scorodite $>$ goethite \\
\hline
\end{tabular}

\section{1 - Programa de amostragem}

A amostragem contemplou: locais onde a área ocupada por resíduos era vasta, locais com diferentes configurações e calibres dos materiais acumulados e portadores de arsenopirite, diferentes relaçóes entre a localização dos acumulados estéreis e a posição de infraestruturas de tratamento - por exemplo, diferentes níveis de proximidade, relativamente às escavaçóes (trincheiras, poços ou galerias) - e, ainda, escorrências peculiares e pontos de acumulação de água. 
As colheitas de água e a medição dos parâmetros expeditos $-\mathrm{pH}$, potencial redox (Eh) e condutividade elétrica (EC) no campo e em laboratório - tiveram lugar entre os meses de fevereiro e maio de 2009. Em cada uma das áreas mineiras foram considerados locais de colheita situados na proximidade ou no interior das escavaçóes (excetuando-se Castelhão).

Tabela 2 - Caracterização das ocorrências scorodíticas nos espaços mineiros em apreço. Simbologia:

[D]disperso; [L]localizado; abundância relativa- $(+)$ pouco abundante, $(++)$ medianamente abundante, $(+++)$ muito abundante; cristalinidade- $[++]$ elevada, [+] baixa, [-] aparentemente geliforme;

[sc] scorodite; [pi] pirite; [goe] goethite; [arst] arsenatos indiferenciados; [ynm] yanomamite;

[farm] farmacossiderite; [sulf] sulfuretos indiferenciados; [qz] quartzo.

\begin{tabular}{|c|c|c|c|c|c|}
\hline $\begin{array}{l}\text { Espaço } \\
\text { mineiro }\end{array}$ & Localização estudada & $\begin{array}{l}\text { Distribuição } \\
\text { (Abundância) }\end{array}$ & $\begin{array}{l}\text { Associaçấo } \\
\text { scorodítica }\end{array}$ & $\begin{array}{c}\text { Descrição da } \\
\text { ocorrência }\end{array}$ & $\begin{array}{l}\text { Cristalini- } \\
\text { dade }\end{array}$ \\
\hline \multirow{3}{*}{ Castelhão } & $\begin{array}{l}\text { Escombreira } \\
\text { de grosseiros }\end{array}$ & $\mathrm{D}(+)$ & sc & $\begin{array}{l}\text { Cristais isolados } \\
\text { sobre qz (Fig. 1) }\end{array}$ & ++ \\
\hline & Escombreira de encosta & $\mathrm{L}(++)$ & $s c+p i$ & $\begin{array}{c}\text { Agregados } \\
\text { cristalinos frágeis } \\
\text { a pulverulentos } \\
\text { sobre sulf } \\
\end{array}$ & - \\
\hline & Escombreira & $\mathrm{D}(++)$ & $\mathrm{sc}+$ goe & $\begin{array}{l}\text { Crustas } \\
\text { revestindo } \\
\text { cavidades em } \\
\text { qz+sulf }\end{array}$ & + \\
\hline \multirow[b]{2}{*}{$\begin{array}{l}\text { Argas- } \\
\text {-Cerquido }\end{array}$} & Afloramento & $\mathrm{D}(+++)$ & $s c+$ goe & $\begin{array}{c}\text { Crustas } \\
\text { consolidadas } \\
\text { em bandas (Fig. 1) }\end{array}$ & - \\
\hline & Trincheira & $\mathrm{L}(+)$ & $s c+\operatorname{arst}$ & $\begin{array}{c}\text { Cristais individu- } \\
\text { ais ou agregados } \\
\text { botrioidais + arst, } \\
\text { em cavidades }\end{array}$ & ++ \\
\hline \multirow[b]{2}{*}{ Tibães } & $\begin{array}{l}\text { Galeria e } \\
\text { Trincheira }\end{array}$ & $\mathrm{L}(+)$ & sc (ynm) & $\begin{array}{c}\text { Crescimento } \\
\text { epitaxial } \\
\text { de sc sobre ynm }\end{array}$ & ++ \\
\hline & Escombreira & $\mathrm{L}(+)$ & $\begin{array}{l}\mathrm{sc}+\text { goe }+ \\
\quad \text { farm }\end{array}$ & $\begin{array}{l}\text { Cristais individu- } \\
\text { ais ou agregados } \\
\text { com farm sobre } \\
\text { goe }\end{array}$ & ++ \\
\hline \multirow{3}{*}{ Adoria } & $\begin{array}{l}\text { Escombreira de gros- } \\
\text { seiros }\end{array}$ & $\mathrm{L}(+)$ & sc & $\begin{array}{c}\text { Agregados } \\
\text { em 'roseta' } \\
\text { sobre qz (Fig. 1) }\end{array}$ & ++ \\
\hline & Escombreira de encosta & $\mathrm{D}(++)$ & sc & $\begin{array}{l}\text { Crustas frágeis } \\
\text { a pulverulentas } \\
\text { sobre qz }\end{array}$ & - \\
\hline & $\begin{array}{l}\text { Escombreira de gros- } \\
\text { seiros }\end{array}$ & $\mathrm{L}(+)$ & $s c+$ arst & $\begin{array}{l}\text { Agregados crista- } \\
\text { linos em esferas } \\
\text { com arst } \\
\text { em fendas de } \\
\text { alteraçáo de sulf }\end{array}$ & ++ \\
\hline \multirow{3}{*}{ Penedono } & $\begin{array}{c}\text { Galeria com marcas de } \\
\text { precipitaçấo no teto e paredes }\end{array}$ & $\mathrm{D}(++)$ & sc & $\begin{array}{c}\text { Crustas } \\
\text { pulverulentas } \\
\end{array}$ & - \\
\hline & Escombreira à boca da mina - & $\mathrm{L}(+++)$ & $\mathrm{sc}+\operatorname{arst}$ & $\begin{array}{c}\text { Blocos com sc } \\
\text { massiva }\end{array}$ & + \\
\hline & Lavaria (tolva) & $\mathrm{L}(++)$ & $s c+$ goe & $\begin{array}{l}\text { Pós e pátinas } \\
\text { (Fig. 1) }\end{array}$ & - \\
\hline
\end{tabular}




\section{2 - Tratamento e preparaçáo das amostras}

Algumas amostras de mão, constituídas por materiais muito friáveis e hidratados, foram sujeitas a secagem e submetidas a sucessivas impregnaçóes com uma resina epoxídica, com o objetivo de obter superfícies com um grau de polimento adequado à análise em microscópio ótico e microssonda eletrónica. Para isso, o corte e o polimento foram realizados sem água, por forma a atenuar os efeitos da solubilização nas superfícies. Este trabalho encontra-se desenvolvido em ALVES et al. (2010).

No laboratório, as águas foram filtradas com membrana de celulose esterilizada, com malha $0.45 \mu \mathrm{m}$. De cada amostra, uma porção foi acidificada com $\mathrm{HNO}_{3} 65 \%$ suprapur Merck e posteriormente processada.

\section{3 - Protocolos analíticos}

A identificação e caracterização mineroquímica das neoformações mineralógicas supergénicas geradas por oxidação foram efetuadas combinando a difração de raios X equipamento PHILIPS com ampola de cobre e cristal monocromador de grafite, $2 \theta=2^{\circ}$ a $70^{\circ}$ - e a análise química pontual com microssonda eletrónica (MSE) - equipamento Hyperprobe Jeol JXA-8500F operando com $15 \mathrm{Kv}$ e 20nA (ver descrição em ALVES et al., 2010).

No caso das águas, a medição de parâmetros em campo foi efetuada com medidor multi-paramétrico - equipamento Orion, model 5 Star, para leitura de EC, pH, Eh e temperatura. Foram usadas as seguintes sondas: elétrodo de pH/ATC Triode, referência 91-07 e célula de condutividade, referência 013010 .

Realizaram-se análises laboratoriais para medição do sulfato por turbidimetria, segundo o Standard Methods for Water Analysis, com a referência 4500E. A alíquota acidificada foi usada para quantificação de metais por espectrometria ótica de emissão com plasma indutivo acoplado (ICP/OES), no laboratório Actlabs (Canada).

\section{3 - Resultados}

A tabela 3 reflete algumas propriedades dos efluentes (E- colhido em escombreira; Gcolhido em galeria) e das águas de fundo regional (R-colhidas a montante dos domínios de influência de acumulados mineiros).

$\mathrm{Na}$ tabela 4 estão patentes composiçôes médias para análises pontuais obtidas em secções de cristais de scorodite (nos casos de Castelhão, Fulão e Tibães) e análise de um núcleo de yanomamite (Tibães-ynm), extraída de uma cavidade de corrosão de arsenopirite (ver ALVES et al., 2010).

Apresentam-se, ainda, as composiçôes pontuais de um agregado cristalino de scorodite de Adoria e de uma crusta pulverulenta de scorodite de Penedono (ambos ilustrados na Fig. 1). $\mathrm{O}$ cálculo de átomos por fórmula teve como base a estequiometria, $\mathrm{A}\left(\mathrm{BO}_{4}\right) \cdot 2 \mathrm{H}_{2} \mathrm{O}$ $[\mathrm{A}=(\mathrm{Fe}, \mathrm{Al}, \mathrm{In}) ; \mathrm{B}=(\mathrm{P}, \mathrm{As})]$. 
Tabela 3 - Características das águas: (E) escombreira; (G) galeria;

(R) fundo regional, dos espaços mineiros em apreço.

\begin{tabular}{ccccccccc} 
& & $\mathrm{T}\left({ }^{\circ} \mathrm{C}\right)$ & $\mathrm{pH}$ & $\mathrm{Eh}(\mathrm{mV})$ & $\mathrm{SO}_{4}(\mathrm{mg} / \mathrm{L})$ & $\mathrm{Fe}(\mathrm{ppb})$ & $\mathrm{As}(\mathrm{ppb})$ & $\mathrm{In}(\mathrm{ppt})$ \\
\hline \multirow{2}{*}{ Castelháo } & $\mathrm{E}$ & 9.8 & 4,18 & 370,8 & 25 & 62,4 & 129,01 & 0,2 \\
& $\mathrm{R}$ & 10 & 4,8 & 358,1 & 3 & 70,9 & 6,80 & 0,3 \\
\hline \multirow{2}{*}{ Argas- } & $\mathrm{E}$ & 8.9 & 4,33 & 259 & 4,4 & 25,1 & 35,28 & 0,4 \\
-Cerquido & $\mathrm{G}$ & 11.2 & 4,3 & 449,4 & 28 & 71,2 & 89,95 & 0,2 \\
& $\mathrm{R}$ & 9.3 & 4,11 & 270,7 & 1,7 & 23,9 & 0,42 & 0,6 \\
\hline \multirow{3}{*}{ Tibães } & $\mathrm{E}$ & 22,2 & 5,21 & 178 & 3,1 & 375,7 & 3,73 & 1,2 \\
& $\mathrm{G}$ & 20.6 & 5,05 & 203 & 3,8 & 293,7 & 5,54 & 1,7 \\
& $\mathrm{R}$ & 18 & 6,85 & 150 & 0,8 & 16,6 & 40,25 & 0,2 \\
\hline \multirow{3}{*}{ Adoria } & $\mathrm{E}$ & 12.2 & 5,85 & 264,8 & 1,2 & 5,3 & 0,92 & 0,1 \\
& $\mathrm{G}$ & 11.6 & 6,16 & 291,1 & 0,7 & 2,6 & 7,19 & 0,1 \\
& $\mathrm{R}$ & 11.5 & 5,3 & 355,4 & 0,1 & 8,1 & 0,43 & $<0.1$ \\
\hline \multirow{3}{*}{ Penedono } & $\mathrm{E}$ & 7 & 2,86 & 498,8 & 79 & 1390,0 & 1647,64 & 3,3 \\
& $\mathrm{G}$ & 6.6 & 4,01 & 444,4 & 18 & 86,4 & 114,61 & 0,5 \\
& $\mathrm{R}$ & 7.3 & 6,59 & 302,5 & 2,2 & 32,8 & 12,20 & $<0.1$ \\
\hline & & & & & & & &
\end{tabular}

Tabela 4 - Variação composicional das scorodites colhidas nos diferentes espaços mineiros. Base de cálculo para as fórmulas estruturais: $\mathrm{A}\left(\mathrm{BO}_{4}\right) \cdot 2 \mathrm{H}_{2} \mathrm{O}[\mathrm{A}=(\mathrm{Fe}, \mathrm{Al}, \mathrm{In}) ; \mathrm{B}=(\mathrm{P}, \mathrm{As})]$.

\begin{tabular}{cccccc|c}
\hline & $\mathrm{Fe}$ & As & In & $\mathrm{P}$ & $\mathrm{Al}$ & $\mathrm{Fe} / \mathrm{As}$ \\
\hline Castelhão & 0,97 & 1,01 & 0,00 & 0,00 & 0,01 & 0,96 \\
Fulão & 0,98 & 0,98 & 0,00 & 0,01 & 0,02 & 1,00 \\
Tibães & 0,98 & 0,97 & 0,01 & 0,02 & 0,02 & 1,01 \\
\hline $\begin{array}{c}\text { Tibães } \\
\text { (ynm) }\end{array}$ & 0,35 & 0,81 & 0,64 & 0,18 & 0,02 & 0,43 \\
\hline $\begin{array}{c}\text { Adoria } \\
\text { Penedono }\end{array}$ & 0,97 & 0,98 & 0,00 & 0,03 & 0,01 & 0,99 \\
\hline
\end{tabular}

\section{4 - Discussão e conclusóes}

Na Fig. 2 A destaca-se, a sombreado, o domínio de sobressaturação correspondente à scorodite, e o domínio de estabilidade da própria scorodite, nos diagramas de ZHU \& MERKEL (2001). A composição das amostras de água estudadas projeta-se nas proximidades com valores de Eh um pouco mais baixos. 
$\boldsymbol{A}$
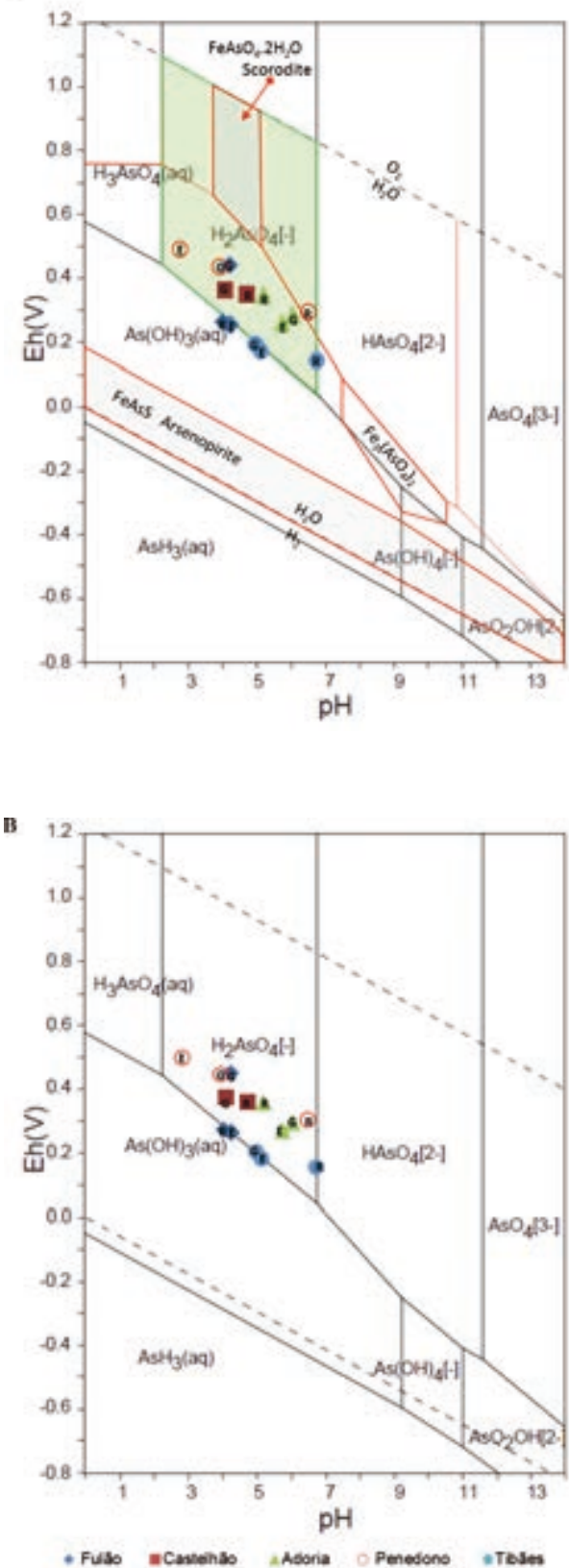

Fig. 2 - Composição da água e efluentes. A - Diagrama Eh-pH para o sistema As-Fe - S - $\mathrm{H}_{2} \mathrm{O}(\mathrm{ZHU} \&$ MERKEL, 2001 - Informação da base de dados Wateq4f, software PHREEQC2). B - Diagrama Eh-pH para o sistema As (TAKENO, 2005 - base de dados "thermo.dat", segundo Lawrence Livermore National Lab (LLNL), software GWB). Símbolos de classificação dos locais de colheita como na tabela 3. 
Tendo em conta as observações efetuadas no campo - atendendo à localização preferencial, dimensão dos cristais e cristalinidade (em DRX) da scorodite, considerando as condiçôes de despejo das partículas e clastos rejeitados com arsenopirite e tendo, ainda, em atenção as características dos efluentes (Fig. 3) - a interação água-scorodite verifica-se a maior Eh e menor pH que a interaçáo com a arsenopirite. Combinando as ilaçóes extraídas das figuras 2 e 3, esta tendência é compatível com a precipitação da scorodite para um incremento de Eh, quando a concentração de arsénio no soluto for [As]>89,95 $\approx 90 \mathrm{ppb}$. Isto no caso de águas que antes da interação têm as características próprias do fundo regional (na envolvência mineira) definido em Tibães.

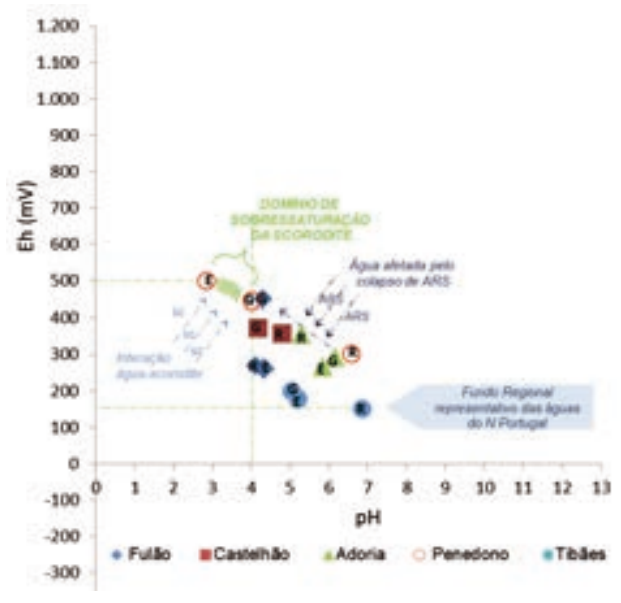

Fig.3 - Localização sobre diagrama Eh/pH dos domínios de interação das águas analisadas com os minerais arsenopirite e scorodite. Símbolos de classificação dos locais de colheita como os da tabela 3.

$\mathrm{Na}$ Fig. 4, os valores projetados relacionam $\mathrm{As}, \mathrm{In}, \mathrm{Fe}_{\mathrm{e} \mathrm{SO}}$ face à variação conjugada dos indicadores de acidez e oxidação/redução.

Os efluentes de Penedono apresentam, generalizadamente, as concentraçóes de iōes em solução mais elevadas. Este facto reflete, certamente, o granulado muito mais fino dos estéreis ali acumulados, os quais, dadas as superfícies específicas muito maiores, devem ser mais reativos na interação com a água e, assim, podem com mais facilidade libertar constituintes.

Excluindo Penedono, em Tibães surgem os mais altos conteúdos de In. Neste sítio mineiro a reatividade dos estéreis (clastos de grandes dimensóes) deverá ser bastante menor. Como resultado também deverá existir uma disponibilidade menor de constituintes para as soluçôes afetadas pela interação química supergénica. Ora, segundo a Fig. 4, os valores de Tibães, especialmente In e Fe nos efluentes, são bastante mais altos do que seria de esperar, considerando a quantidade de arsenopirite observada e disponível para a interação com a água. Tais valores são, contudo, compatíveis com a precipitação de scorodite com alto In e yanomamite (tabela 4 e ALVES et al., 2010) e, portanto, na paragénese primária de Tibães deveriam existir conteúdos altos de In em outras fases sulfuretadas e não necessariamente na arsenopirite. Atendendo à maior dimensão dos cristais da scorodite, 
maior diversidade mineralógica das suas paragéneses e também pelo facto de a yanomamite poder ser uma fase nuclear em cristais compósitos com bordo de arsenopirite, é de equacionar uma precipitação precoce da fase com In, possivelmente, ainda no depósito primário, em condiçóes supergénicas ou até hidrotermais de baixa temperatura.
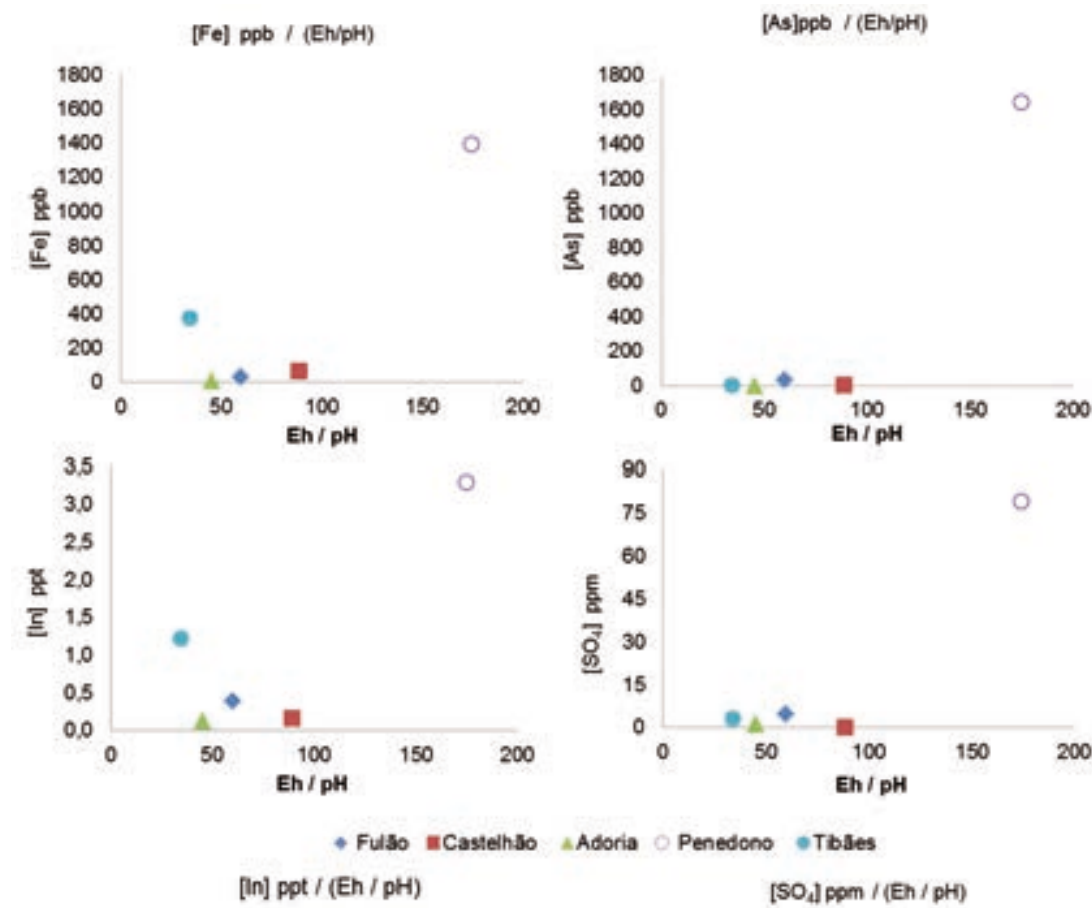

Fig. 4 - Variação de algumas concentrações de constituintes móveis perante a variação do descritor $\mathrm{Eh} / \mathrm{pH}$ dos efluentes.

Agradecimentos - À Eng. ${ }^{a}$ Fernanda Guimarães e Prof. Machado Leite pela utilização da microssonda do Laboratório Nacional de Energia e Geologia (LNEG) ao abrigo do protocolo REEQ/18/CTE/2005 - âmbito do Programa Nacional de Reequipamento Científico. Este trabalho recebeu apoio da FCT através da bolsa de doutoramento SFRH/ $\mathrm{BD} / 42485 / 2007$.

\section{Referências Bibliográficas}

ALVES, R., LEAL GOMES, C. \& VALENTE, T. (2010) - A associação yanomamite-scorodite e a mineralização supergénica de In em detritos mineiros de zonas de cisalhamento com W-Au-As Zn - Norte de Portugal. e-Terra, Geosciences on-line Journal, Geotic, 16. http://metododirecto.pt/CNG2010/ index.php/ vol/article/viewFile/421/155. (consultado em 2011.12.20). 
TAKENO, N. (2005) - Atlas of Eh-pH diagrams Intercomparison of thermodynamic databases. Geological Survey of Japan Open File Report No.419, National Institute of Advanced Industrial Science and Technology. Research Center for Deep Geological Environments, 280 p.

VALENTE, T. \& LEAL GOMES, C. (1998) - Tipologia e Evolução dos Materiais de Neoformação Supergénica Detectados na Escombreira da Mina de Valdarcas (Vila Nova de Cerveira - N. Portugal) - implicações ambientais. Caderno Lab. Xeolóxico de Laxe, 23, p. 43-57.

ZHU, Y. \& MERKEL, B. J. (2001) - The dissolution and solubility of scorodite, FeAsO4•2H2O evaluation and simulation with PHREEQC2. Wiss. Mitt Inst. fur Geologie, TU Bergakedemie Frieberg, Germany, 18 , p. $1-12$. 